\title{
THERMAL BEHAVIOUR ANALYSIS OF COMPLEX JOINTS FOR AN ENERGY EFFICIENT SCHOOL BUILDING
}

\author{
Szilárd KARDA, ${ }^{1}$ Tamás NAGY-GYÖRGY, ${ }^{2}$ József BOROS ${ }^{3}$ \\ Politehnica University of Timișoara, Civil Engineering Department. Timișoara, Romania \\ ${ }^{1}$ szilard.karda@student.upt.ro \\ 2 tamas.nagy-gyorgy@upt.ro \\ 3 iosif.boros@student.upt.ro
}

\begin{abstract}
Energy-efficient buildings have received increasing attention in recent times as they represent a direction that promotes the objectives of a sustainable, competitive and decarbonized energy policy. In order to meet the minimum requirements of the nearly zero-energy buildings (nZEB) the thermal characteristics of the envelope play an important role. The aim of the paper is to present and analyse the thermal behaviour of complex joints for an energy efficient school building, for which the formation of thermal bridges has been reduced by applying improved geometrical and technological solutions. Since most of the thermal bridge catalogues did not provide updated details for the studied joints, numerical calculations, as two-dimensional finite elements thermal simulations, were performed to determine thermal transmittance coefficients and the U-value..
\end{abstract}

Keywords: energy efficiency, thermal bridges, complex joints, thermal transmittance coefficient.

\section{Introduction}

The issue of energy consumption has received increased attention in the European Union in recent decades. In 2007, EU leaders set a target of reducing the EU's annual energy needs by $20 \%$ by 2020 , and by continuing this line of action, Member States would achieve a $32.5 \%$ decline by 2030. Energy efficiency measures are not only a means of reducing greenhouse gas emissions and achieving a sustainable energy supply, but also a way of increasing the competitiveness of nations [1], which is the reason why this action plan is a strategic priority for the European Union. Buildings are currently responsible for $40 \%$ of the final energy consumption and $36 \%$ of $\mathrm{CO}_{2}$ emissions. Therefore, in order to increase the energy performance of new and existing buildings, the EU Directive 2010/31/EU contains a number of requirements, of which it is important to highlight near-zero energy buildings (nZEB).

NZEBs are high energy efficiency buildings in which at least $30 \%$ of used energy, whether it is nearly zero or of a very low amount, must come from renewable sources [2]. One of the basic requirements of the current legal framework is that all new buildings in Romania that are put into use on the basis of a building permit issued after 31 December 2020 must be nearly zero-energy buildings [3].

InRomania,theaverageprimaryenergyconsumption of buildings is approximately $250 \mathrm{kWh} / \mathrm{m}^{2}$ per year, which is $25 \%$ higher than the EU average, due to climatic conditions and the predominance of obsolete and low efficiency buildings. The worst situation is that of educational establishments, as they exceed the annual energy demand of $354 \mathrm{kWh} / \mathrm{m}^{2}$, contrasted with the primary energy consumption of ZNEB facilities, which can be between 100 and $185 \mathrm{kWh} / \mathrm{m}^{2}$ per year, depending on the regional climate. Energy efficiency is significantly influenced by the thermal characteristics of building elements, the location and orientation of the building, heating and air-conditioning systems, natural and mechanical ventilation, built-in lighting, passive solar systems, 
shading, indoor climatic conditions, and internal heat loads [4].

This paper examines the joints of the spatial boundary structure of a school building that can serve as a solution to reduce thermal bridges. As more than $50 \%$ of the energy consumption of buildings is used for heating, in order to increase energy efficiency, this ratio may decrease significantly if the building envelope is adequately insulated and if the number of areas where thermal bridges can form is reduced to a minimum. By paying more attention to the possible thermal bridges at junctions, the heat transfer coefficients of the structures and the specific heat loss can be optimized.

\section{Nearly zero-energy school building}

The new wing of the János Arany Theoretical High School in Salonta was handed over in 2017, and is the first nearly zero-energy educational building in Romania that also meets the requirements of passive houses. The building has a usable heated area of $3496 \mathrm{~m}^{2}$. Its reinforced concrete load-bearing frame structure lies on a beam grid base. There is $20 \mathrm{~cm}$ XPS thermal insulation under the floor slab. The side partitions consist of $25 \mathrm{~cm}$ thick aerated concrete masonry and $15 \mathrm{~cm}$ rock wool, the windows are of a 6-chamber plastic window structure and a 3-layer glass structure. The reinforced concrete slab under the unheated attic and the bottom closing slab was thermally insulated with $25 \mathrm{~cm}$ rock wool.

The joints are examined in a stationary state. For numerical simulation, it is necessary to determine the geometry of the structure, the thermal capacity of the materials that make up the geometry, the thermal conductivity, and the external and internal boundary conditions [5].

The modelling value of the outside temperature can be determined as a function of the country's climate zone. Salonta is located in the second climate zone, so the modelling outdoor temperature is $-15^{\circ} \mathrm{C}$. The internal temperature of the building is $+18^{\circ} \mathrm{C}$, which can be calculated from the weighted average of the temperatures specified for each room, according to their purpose. The temperature of the attic is determined by the modelled outdoor temperature, the required indoor temperature and the resulting thermal resistance of the space delimiting elements. Thus, the resulting room temperature in the unheated space was $-11.35^{\circ} \mathrm{C}$. According to the statistical average of the outdoor atmospheric conditions, the humidity value is defined as $70 \%$, while for the indoor air temperature conditions the humidity is set to $60 \%$ by requirement. External and internal surface thermal resistance used in the calculations, $25 \mathrm{~W} / \mathrm{m}^{2} \mathrm{~K}$ and $8 \mathrm{~W} / \mathrm{m}^{2} \mathrm{~K}$, respectively..

\section{Calculation of thermal bridges and U-values}

The thermal transmittance, or the U-value, is a characteristic of the thermal insulation of a surface, which expresses the amount of heat flowing through an area of one unit of a given structure under the influence of a unit of temperature. However, the actual heat transfer of the space delimiting structure is influenced by various repetitive linear and point-like inhomogeneities [6], therefore the corrected $U^{\prime}$ value can be calculated according to the following formula (1):

$$
U^{\prime}=\frac{1}{R_{s i}+\sum_{i} \frac{d_{i}}{\lambda_{i}}+R_{s e}}+\frac{\sum(\psi \cdot l)}{A}+\frac{\sum \chi}{A}\left[\frac{W}{m^{2} K}\right]
$$

where

$-R_{s e}$ and $R_{s i}$ - external and internal surface thermal resistance $\left[\mathrm{m}^{2} \mathrm{~K} / \mathrm{W}\right]$;

$-d_{i}-$ the thickness of the structural layer [m];

$-\lambda_{i}$ - the thermal conductivity of the structural layer $[\mathrm{W} / \mathrm{mK}]$;

$-l \quad-$ the length of the linear thermal bridge [m];

$-\psi \quad$ - the linear thermal transmittance [W/mk];

$-A$ - the surface of the delimiting element $\left[\mathrm{m}^{2}\right]$;

$-\chi \quad$ - the point thermal transmittance.

Thermal bridges are located in those areas of the boundary structures where, due to varying layer thickness, thermal conductivity, and different outside/inside dimensions, a multidimensional heat flow and temperature distribution is developed [7]. In addition to line and point-like heat losses, thermal bridges can cause problems with thermal comfort and building structure, so their reduction is essential. The extent of thermal bridges is determined by linear (2) and point heat transmittance coefficients (3).

$$
\begin{aligned}
& \psi=\frac{L_{2 D}-\sum U \cdot A}{l}[W / m K] \\
& \chi=\frac{\Phi}{\Delta T}-U \cdot A[W / K]
\end{aligned}
$$

where

$-L_{2 D}$ - thermal bridge factor from 2-dimensional calculations $[\mathrm{W} / \mathrm{mK}]$; 
$-U$ - the initial thermal transmission coefficient $\left[\mathrm{W} / \mathrm{m}^{2} \mathrm{~K}\right]$;

$-\Phi-$ the heat flow formed at the point [W];

$-\Delta T$ - the difference between outdoor and indoor temperature $\left[{ }^{\circ} \mathrm{C}\right]$.

The thermal simulation of the joints was performed with the HTflux finite element software [8], during which the thermal bridge factors, heat flows, heat flow densities and temperature distribution were determined.

\subsection{Roof slab}

The insulation system of the roof slab that separates the heated and unheated space of the building consists of a 10 and $15 \mathrm{~cm}$ thick rock wool layer, in which the thermal transmittance value is $0,150 \mathrm{~W} / \mathrm{m}^{2} \mathrm{~K}$ (Table 1 ). The attic is enclosed by a timber roof whose structural elements rely on the reinforced concrete roof slab, thus changing the thickness and continuity of the thermal insulation where the post and the tie beam are in contact with the slab. In this case the heat flow in this area is increased.

In order to reduce the point and linear thermal bridges at the posts, the second $10 \mathrm{~cm}$ thick insulation layer remained above the tie beam and the post was covered with a $15 \mathrm{~cm}$ thick mineral wool to the bottom of the collar beams (Figure 1).

In the case of the threaded rods used to fasten timber beams to the RC slab, point thermal bridges are formed. Taking into account these points leads to a more precise $U$ value

In finite element modelling, the heat flux in the tie beam is $4.758 \mathrm{~W} / \mathrm{m}$, and the difference between outdoor and indoor temperature is $29.37^{\circ} \mathrm{C}$. Determining the 2-dimensional thermal bridge factor (L2D), the linear thermal transmittance under the post is $0.017 \mathrm{~W} / \mathrm{mK}$ (Figure 2).

In the design of the passive houses, joints with a linear thermal transmittance below $0.01 \mathrm{~W} / \mathrm{mK}$ are called "thermal bridge-free" details [9].

The $0.744 \mathrm{~W}$ heat flow generated at the bottom of the post determines a point thermal transmittance of $0.0219 \mathrm{~W} / \mathrm{K}$. The threaded rods are not in direct contact with the lower temperature of the attic, the value of the point thermal bridge $\chi$ determined by them is a negligible $0.0006 \mathrm{~W} / \mathrm{K}$. In the absence of thermal insulation of the attic posts, $\Psi$ and $\chi$ would increase significantly to $0.075 \mathrm{~W} / \mathrm{mK}$ and $0.0314 \mathrm{~W} / \mathrm{K}$, respectively.

In order to improve the thermal bridges, the thermal insulation layer covering the eaves purlin extends between the rafters to the end of the closing slab (Figure 3), where it is connected with
Table 1. Thermal transmittance of the roof slab.

\begin{tabular}{|l|c|c|}
\hline \multicolumn{1}{|c|}{ Layer order } & $\begin{array}{c}\lambda \\
{[\mathbf{W} / \mathbf{m K}]}\end{array}$ & $\begin{array}{c}\text { Thickness } \\
{[\mathbf{c m}]}\end{array}$ \\
\hline Rock wool & 0.039 & 25 \\
\hline Polythene sheet & 0.290 & 0.2 \\
\hline RC slab & 1.740 & 13 \\
\hline Cement plaster & 0.930 & 1.5 \\
\hline \multicolumn{2}{|c|}{ U-value $\left[\mathrm{W} / \mathrm{m}^{2} \mathrm{~K}\right]$} \\
\hline
\end{tabular}

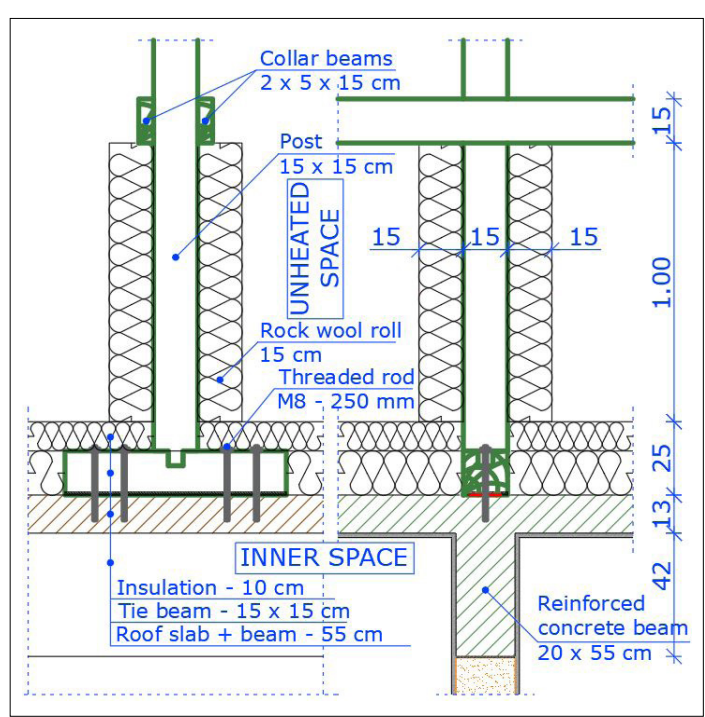

Figure 1. Thermal insulation system of the attic post.

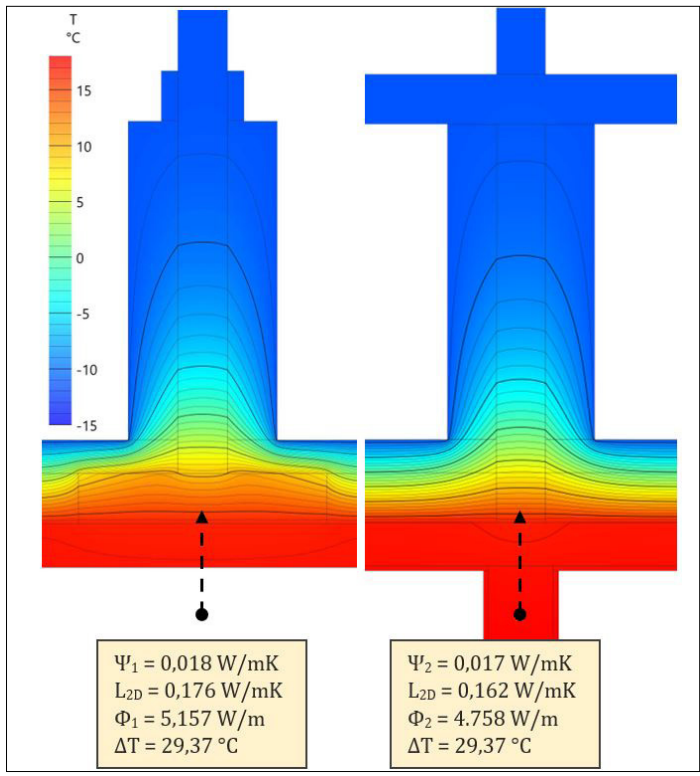

Figure 2. Temperature distribution and $\Psi$ values of insulated attic posts. 


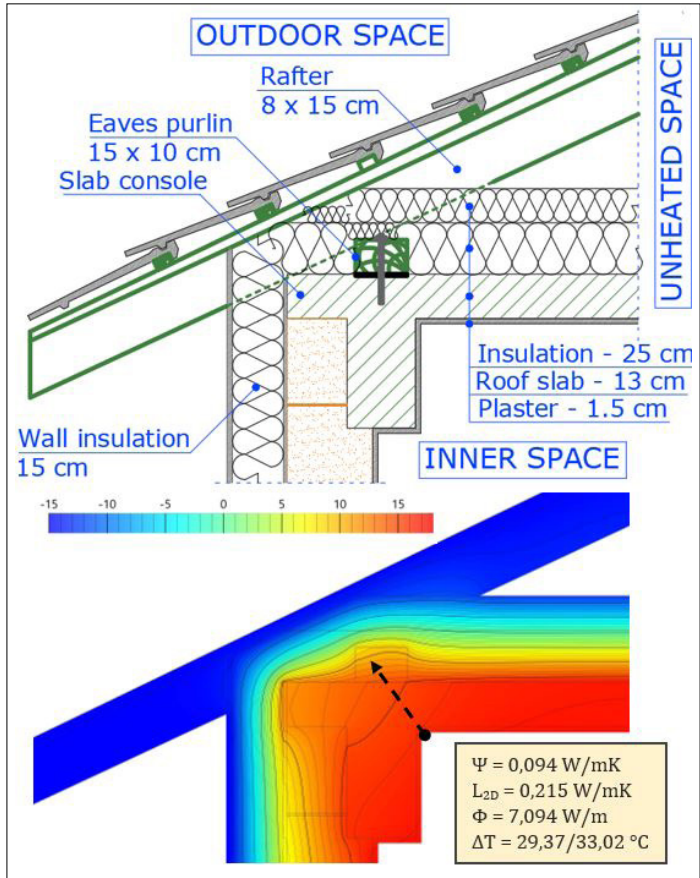

Figure 3. Thermal insulation and $\Psi$ value of the eaves purlin.

the external facade insulation, thus maintaining the continuity of the thermal envelope.

Without direct contact with the external low temperature on the eaves purlin, the resulting $\Psi$ value is $0.094 \mathrm{~W} / \mathrm{mK}$, instead of $0.183 \mathrm{~W} / \mathrm{mK}$. This still results in increased heat loss at the inner corner of the beam slab, but the positioning of rafters and structural elements did not allow for a more favourable option for reducing the thermal bridge. The coefficients of point thermal bridges created by galvanized threaded rods are $0.0006 \mathrm{~W} / \mathrm{K}$ per piece.

Due to adjoining buildings on the east and north sides of the building, the firewalls extend all the way to the top of the gable roof, therefore linear thermal bridges are formed at the two side strips of the closing slab. As a result, the facade thermal insulation of the attic outer wall follows the thickness of the lower levels, and, at the junction of the closing slab and the unheated space, additional thermal insulation on the inside of the wall up to a height of $2.00 \mathrm{~m}$ was added (Figure 4). The layers and thermal transmission coefficient of the external facade wall below and above the attic are shown in Table 2.

The steel studs of the screw plastic dowels used for the thermal insulation of the facade walls create point thermal bridges in the thickness of the
Table 2. U value of external masonry and attic firewall.

\begin{tabular}{|l|c|c|}
\hline \multicolumn{1}{|c|}{ Layer order } & $\begin{array}{c}\lambda \\
{[\mathbf{W} / \mathbf{m K}]}\end{array}$ & $\begin{array}{c}\text { Thickness } \\
\text { [cm] }\end{array}$ \\
\hline Cement plaster & 0.930 & 1.5 \\
\hline AAC wall & 0.109 & 25 \\
\hline Adhesive mortar & 0.430 & 1 \\
\hline Rock wool & 0.0384 & 15 \\
\hline Adhesive mortar & 0.430 & 1 \\
\hline Primer & 0.430 & 0.2 \\
\hline Decorative plaster & 1.280 & 0.3 \\
\hline U-value under roof slab [W/m2K] & 0.155 \\
\hline + Adhesive mortar & 0.430 & 1 \\
\hline + Rock wool & 0.0384 & 15 \\
\hline \multicolumn{2}{|l|}{ U-value above roof slab [W/m² $]$} & 0.097 \\
\hline
\end{tabular}

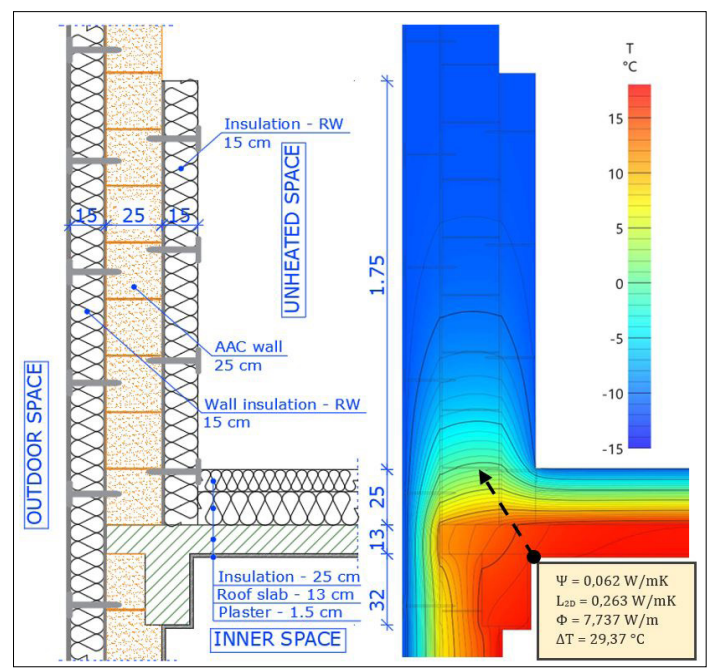

Figure 4. Thermal insulation and $\Psi$ value of the external wall (firewall) - roof slab joint.

thermal insulation and the supporting elements. The dowels used in the building have a point thermal transmittance of $0.00198 \mathrm{~W} / \mathrm{K}$ [10], and increase the thermal conductivity of the rock wool by $6 \%$, thus negatively affecting the initial thermal resistance of the facade walls and the lower closing slab.

During the simulation, a heat flux of $7.737 \mathrm{~W} / \mathrm{m}$ was generated at the junction of the external wall and the closing slab, so the value of the linear thermal transmittance was $0.062 \mathrm{~W} / \mathrm{mK}$. The rock wool sheets installed on the inside of the firewall reduced the heat flow in the inner corner of the barrier by almost half. Without the extra thermal insulation, the $\Psi$ value would be $0.120 \mathrm{~W} / \mathrm{mK}$. 


\subsection{Bottom closing slab}

The thermal insulation of the bottom closing slab was made with $25 \mathrm{~cm}$ rock wool, whose layers (Table 3) determined the U-value of $0.131 \mathrm{~W} / \mathrm{m}^{2} \mathrm{~K}$.

For the thermal envelope the $25 \mathrm{~cm}$ insulation was maintained around the reinforced concrete beams (Figures 5, 7, 8). In order to reduce the point thermal bridges at the junction of the columns and the slab, the entire height of the pillar was coated with $5 \mathrm{~cm}$ of rock wool, ruling out the contact between the reinforced concrete structure with the outside space. For the facades, the cantilever slab was dimensioned and modelled so that the aerated concrete masonry extends 5 $\mathrm{cm}$ beyond the outer side of the reinforced concrete column, therefore the thermal insulation in column lane is $20 \mathrm{~cm}$ thick. This compensates for the unfavourable thermal conductivity of the reinforced concrete.

At the junction of the closing beam slab and the reinforced concrete columns, the vast majority of the heat loss leaves in the direction of the columns, as the vertical support structure is considered to be a fully outdoor element. Due to the $45 \times 45 \mathrm{~cm}$ cross section and position of the reinforced concrete pillar, this study considers this joint to be a linear thermal bridge and determines the value of $\Psi$ in the inner corner of the heated space.

Due to the unfavourable thermal conductivity of the concrete and the heat capacity resulting from the column size, the heat flow at this point of the thermal envelope reaches $21.946 \mathrm{~W} / \mathrm{m}$. The value of the 2-dimensional thermal bridge factor obtained during the simulation is $0.665 \mathrm{~W} / \mathrm{mK}$, and the linear thermal transmittance coefficient is $0.464 \mathrm{~W} / \mathrm{mK}$ (Figure 6). Given that these thermal bridges only appear in 3 spots of the closing slab, it does not affect the U' value significantly. Much more significant heat loss can occur in the edge beam area of the slab.

Continuous thermal insulation of the intermediate beam minimized thermal bridges, with a linear thermal transmittance coefficient of $0.017 \mathrm{~W} / \mathrm{mK}$ (Figure 7). When the junction of the reinforced concrete beam receives less attention and the bottom is covered with only $5 \mathrm{~cm}$ of thermal insulation, the value of $\Psi$ reaches $0.096 \mathrm{~W} / \mathrm{mK}$, therefore the heat flux in through the beam increases sixfold.

The heat flow around the edge beam of the closing slab is considerably higher than in the case of
Table 3. Thermal transmittance of the bottom closing slab.

\begin{tabular}{|l|c|c|}
\hline \multicolumn{1}{|c|}{ Layer order } & $\begin{array}{c}\lambda \\
\text { [W/mK] }\end{array}$ & $\begin{array}{c}\text { Thickness } \\
\text { [cm] }\end{array}$ \\
\hline Ceramic tiles & 2.030 & 1 \\
\hline Adhesive mortar & 0.930 & 1 \\
\hline Screed & 0.930 & 5 \\
\hline Polythene sheet & 0.290 & 0.2 \\
\hline EPS insulation & 0.042 & 3 \\
\hline RC slab & 0.930 & 13 \\
\hline Adhesive mortar & 0.430 & 1 \\
\hline Rock wool & 0.0384 & 25 \\
\hline Adhesive mortar & 0.430 & 1 \\
\hline Primer & 0.430 & 0.2 \\
\hline Decorative plaster & 1.280 & 0.3 \\
\hline U-value $\left[\mathrm{W} / \mathrm{m}^{2} \mathrm{~K}\right]$ & & 0.131 \\
\hline
\end{tabular}

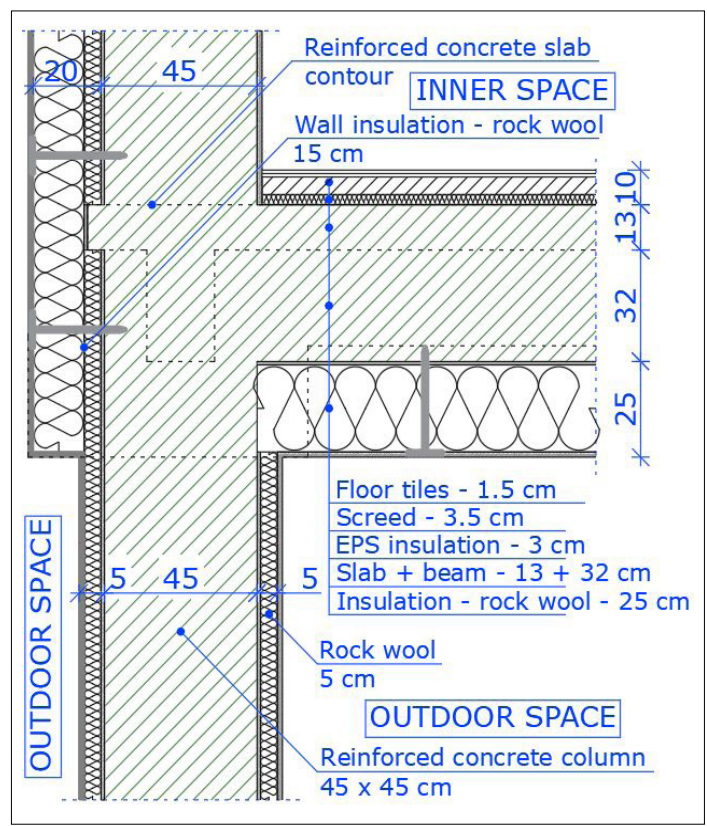

Figure 5. RC column - closing slab joint.

intermediate beams, due to the geometry of the joint. The thermal envelope is continuous in this area as well, and it was possible to place a $32.5 \mathrm{~cm}$ thick thermal insulation layer on the outer side of the reinforced concrete beam. Therefore, the obtained linear thermal transmittance is $0.105 \mathrm{~W} / \mathrm{mK}$ (Figure 8). When there is no additional thermal insulation, the value of $\Psi$ exceeds $0.174 \mathrm{~W} / \mathrm{mK}$. 


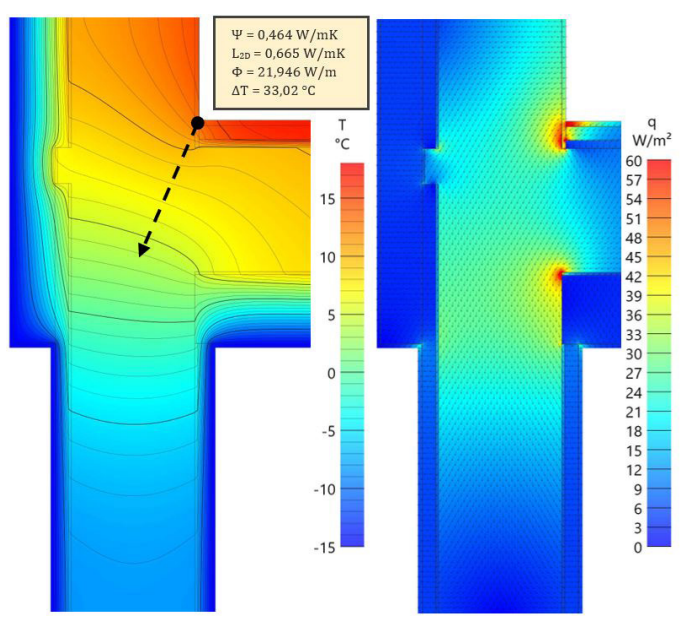

Figure 6. RC column - closing slab temperature distribution and heat flux density.

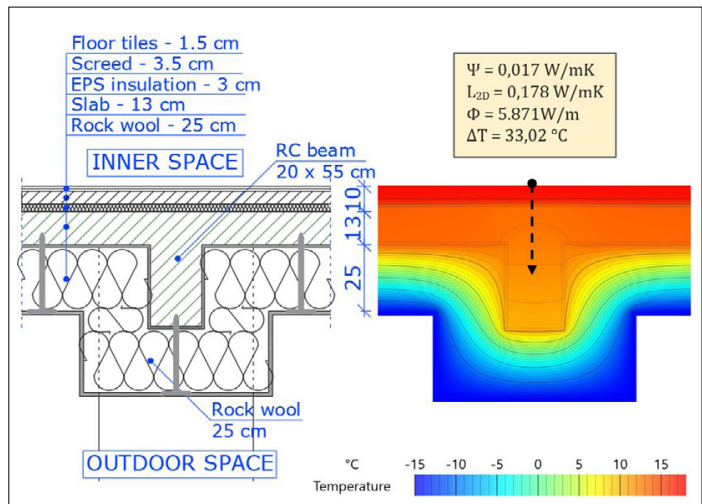

Figure 7. Thermal insulation and $\Psi$ value of the intermediate RC beam.

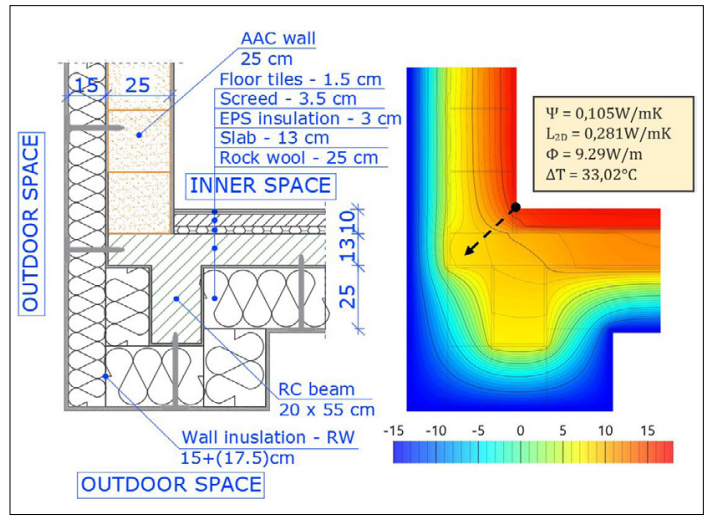

Figure 8. The reinforced concrete edge beam of the closing slab.
Table 4. U'-values of space delimiting elements.

\begin{tabular}{|c|c|c|c|c|}
\hline & \multicolumn{2}{|c|}{ Roof slab } & \multicolumn{2}{c|}{$\begin{array}{c}\text { Lower closing } \\
\text { slab }\end{array}$} \\
\hline$U\left[\mathrm{~W} / \mathrm{m}^{2} \mathrm{~K}\right]$ & \multicolumn{2}{|c|}{0.150} & \multicolumn{2}{c|}{0.131} \\
\hline$A\left[\mathrm{~m}^{2}\right]$ & \multicolumn{2}{|c|}{946.90} & \multicolumn{2}{|c|}{35.40} \\
\hline \multirow{3}{*}{$\Psi \cdot l[\mathrm{~W} / \mathrm{K}]$} & 0.017 & 42.75 & 0.464 & 1.35 \\
\cline { 2 - 5 } & 0.094 & 121.8 & 0.017 & 3.40 \\
\cline { 2 - 5 } & 0.062 & 31.10 & 0.105 & 13.75 \\
\hline \multirow{3}{*}{$\chi \cdot n[\mathrm{~W} / \mathrm{K}]$} & 0.0314 & 57 & \multicolumn{2}{|c|}{0.00} \\
\cline { 2 - 5 } & 0.0008 & 57 & \multicolumn{2}{|c|}{0.00} \\
\cline { 2 - 5 } & 0.0008 & 97 & \multicolumn{2}{|c|}{0.00} \\
\hline \multirow{2}{*}{$U^{\prime}\left[\mathrm{W} / \mathrm{m}^{2} \mathrm{~K}\right]$} & \multicolumn{2}{|c|}{0.166} & \multicolumn{2}{|c|}{0.191} \\
\hline
\end{tabular}

\subsection{Thermal transmittance coefficients}

The improved thermal transmittance of the two types of space-delimiting elements is determined by the initial U-value and the linear and point thermal transmittance. As can be seen in Table 4 . the large base area of the attic slab has a positive effect on the calculation of the extent of thermal bridges and as heat losses have been minimized, the initial U value has increased by $10.6 \%$. In the case of the closing slab, that has two areas where the thermal bridges have an elevated value, on a relatively small surface, the specified thermal transmittance increased by $45.80 \%$.

$67 \%$ of the thermal bridges in the slab are made up of edge beams, where the reduction of linear heat losses can only be achieved with a significant aesthetic compromise due to the geometric shape of the joint. At the junction of the reinforced concrete columns and the closing slab it is possible to reduce the formation of the thermal bridge if the column is surrounded by not $5 \mathrm{~cm}$ of rock wool, but 15 or $20 \mathrm{~cm}$. With the first solution the linear thermal transmittance decreases to $0.332 \mathrm{~W} / \mathrm{mK}$. With the second variant it decreases to only $0.295 \mathrm{~W} / \mathrm{mK}$. In the case of RC columns, therefore, an additional $10 \mathrm{~cm}$ thick thermal insulation can be used, during which the heat loss at these points would be reduced by $40 \%$.

Comparing the applied thermal insulation with the traditional insulation solutions (Figure 9), it can be concluded that the thermal transmittance would deteriorate by an additional $10 \%$ if the continuity of the thermal envelope and the additional thermal insulation of the posts and firewalls were not taken into consideration. The resulting U'-value of $0.183 \mathrm{~W} / \mathrm{m}^{2} \mathrm{~K}$ would degrade the initial thermal resistance by almost $22 \%$. 


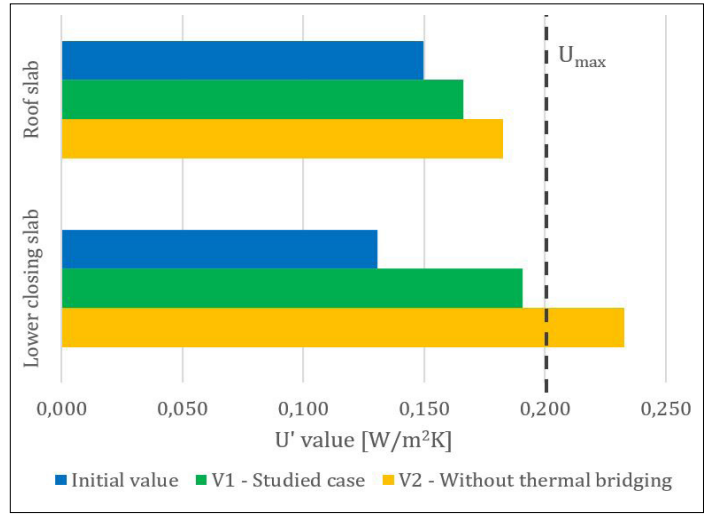

Figure 9. Comparison of U'-values.

Using conventional thermal insulation solutions for the lower closing slab the heat transfer coefficient is $0.233 \mathrm{~W} / \mathrm{m}^{2} \mathrm{~K}$, increasing the heat loss by a further $20 \%$ and thus exceeding the maximum U-value required for closing slabs, which is $0.20 \mathrm{~W} / \mathrm{m}^{2} \mathrm{~K}$.

\section{Conclusions}

Additional thermal insulation for the posts and firewalls of the studied attic floor are a solution that can be used in unheated spaces to reduce linear and point thermal bridges at structural elements. Furthermore, the point thermal bridge created by the threaded rods does not significantly affect the heat transfer coefficient of the thermal envelope.

In the case of the lower closing slab, the geometric design of the space-delimiting elements is a disadvantage in terms of reducing thermal bridges, and in the case of building structures with a smaller surface area, their thermal conductivity deteriorates to an even greater extent. However, increasing the thermal insulation thickness of the reinforced concrete columns can have a positive effect on the formation of heat losses at the slab.

In the case of the studied building boundary elements, it can be stated that heat losses can be reduced by up to $20 \%$ if more attention is paid to the geometries and thermal engineering solutions of the joints. By minimizing the formation of thermal bridges, thermal transmittances (U'-values) can be optimized so that it is not necessary to increase the thickness of the thermal insulation over the entire surface.

\section{References}

[1] Directive (EU) 2018/2002 of the European Parliament and of the Council of 11 December 2018 amending Directive 2012/27/EU on energy efficiency.

[2] Directive 2010/31/EU of the European Parliament and of the Council of 19 May 2010 on the energy performance of buildings.

[3] 13/2016: Ordonanță pentru modificarea și completarea Legii nr. 372/2005 privind performanța energetică a clădirilor.

[4] Daniel D., Tănasă C., Stoian V., Brata S., Stoian D., Nagy-György T., Floruț S. C.: Passive house design: An efficient solution for residential buildings in Romania. Energy for Sustainable Development. 32. (2016) 99-109. https://doi.org/10.1016/j.esd.2016.03.007

[5] Boros I., Tănasă C., Stoian V., Daniel D.: Thermal studies of specific envelope solutions for an energy efficient building. Key Engineering Materials, 660. (2015) 192-197.

https://doi.org/10.4028/www.scientific.net/ KEM.660.192

[6] Mc001/1-2006: Methodology for calculation of energy performance of building. The building envelope.

[7] EN ISO 10211:2017 - Thermal bridges in building construction - Heat flows and surface temperatures - Detailed calculations

[8] HTflux - Hygric and Thermal Simulation Software (accessed on: 2020 okt. 20.).

https://www.htflux.com/

[9] Passipedia - The Passive House Resource https://passipedia.org/ (accessed on: 2020 okt. 20.).

[10] Karda Sz., Nagy-György T., Daniel D., Boros I.: Analysis of the thermal behaviour of a glass fibre reinforced polyamide fastener. In: $18^{\text {th }}$ International Technical-Scientific Conference on Modern Technologies for the $3^{\text {rd }}$ Millennium. Oradea, Romania, 2019. 217-222. 